\title{
Exploring the Garment Fit paradigm from a Sustainability Perspective and its Meaning for First- Cycle and Second-Cycle Fashion Retailers
}

\author{
Tracy Cassidy* \\ Department of Fashion \& Textiles, School of Art \& Design, University of Huddersfield, UK
}

Submission: October 25, 2017; Published: November 16, 2017

*Corresponding author: Tracy Cassidy, Department of Fashion \& Textiles, School of Art \& Design, University of Huddersfield, UK, Tel no: +44(0)1484 472653; Email: T.D.Cassidy@hud.ac.uk

\begin{abstract}
Since the societal and industrial move away from tailored clothing to ready-made garments, it has been suggested that the need for an optimal sizing system has being a constant challenge for the mass-production fashion industry sector and for consumers to acquire well fitting garments Ashdown [1]. However, despite inconsistencies in garment sizing among retailers, which some say serves to confuse, and in some cases infuriate consumers Brown [2], and despite the current economic downturn, clothing remains a high priority for women. In theory, fit can also be considered a barrier to purchase decisions in the second-cycle retail sector though some vintage consumers are prepared to alter clothing or to pay to have it altered to fit Cassidy \& Bennett [3]. As the online shopping habit increases for both first- and second-cycle products, for fashion retailers operating mail order and on-line shopping channels fit in particular is considered to be a challenge as consumers cannot take advantage of trying garments on before buying, which is believed to be a fundamental part of the purchase-decision process and contributes to reducing the risk of high levels of product returns Nellis [4]. This study examines garment fit from a sustainability perspective to conceptually re-think the fit paradigm and debate.
\end{abstract}

Keywords: Fit; Sizing; Consumer; Retail; Garments

\section{Introduction}

Garment fit is a complex issue that, as [5] proposes, is highly dependent upon the wearer's taste. In addition to consumer preferences, Bye, [6] suggest that garment function and purpose plus the involved company's goals are also important concerns. When regarding fit as a critical element of brand image [7], many fashion retailers prioritise on sizing for their target market [8]. However this practice has resulted in discrepancies in garment sizes across the retail sector [2] and while sizing standards should help consumers to quickly select garments that will give a good fit, in practice this does not happen Brown and Rice .Yet, Brown and Rice also believe that with a standard sizing system fewer consumers would actually be catered for due to differences in individual body shapes, sizes and proportions. [9] strongly believe that it is unrealistic to expect the entire population to be catered for through mass production and that the extremes may require be spoke made-to-measure garments.

Winks also suggests that even if a garment is fashionable and of high quality, if it is ill-fitting consumers will still experience dissatisfaction and sales will suffer; and with the growth of online shopping, [10] foresees fashion consumers further demanding more accurate sizing information. From a logistics and financial perspective retailers would greatly benefit from fewer returns from online shoppers, many of which are due to fit discrepancies [8]. Furthermore, [11] reports that half of the UK female population are expected to be obese by 2050 demanding more plus-sized garments, and as body fat is known not to evenly distribute itself around the body, in this event body forms used for manufacturing clothing will require further alteration. In addition, the continuing trend for vintage and retro clothing poses problems related to fit affecting the potential sale of second hand garments both in-store and online. This study considers fit from a fashion consumer perspective in order to rethink fit issues for the fashion retail sector.

\section{Aim and Objectives}

The aim of this study is to assess garment fit from a fashion consumer perspective for the betterment of first- and secondcycle fashion retail provision.

\section{Objectives:}

a. To better understand the typical fashion consumer's general levels of garment fit satisfaction 
b. To establish relationships between fit satisfaction and the brand loyalty concept

c. To explore variations in women's clothing size sand body sizes to better understand how consumers cope with sizing differences when considering a purchase

d. To conceptually re-think fit as a platform for further research in relation to first- and second-cycle fashion

\section{Methodology}

An initial questionnaire survey was conducted with 50 randomly selected females in the city centre of Manchester, UK to understand the importance of fit for typical UK consumers when purchasing garments and to establish the relationship between fit and brand loyalty. Figure 1 shows the short questionnaire; questions 5 and 6 were used to ensure a crosssection of age and dress size ranges were obtained; the results are given as percentages in the figure. A second questionnaire survey, using 58 randomly selected female respondents found in the same location was later conducted to better understand the importance of fit in relation to the shopping experience, thus further exploring consumer satisfaction. The questionnaire and the results are shown in Figure 2.

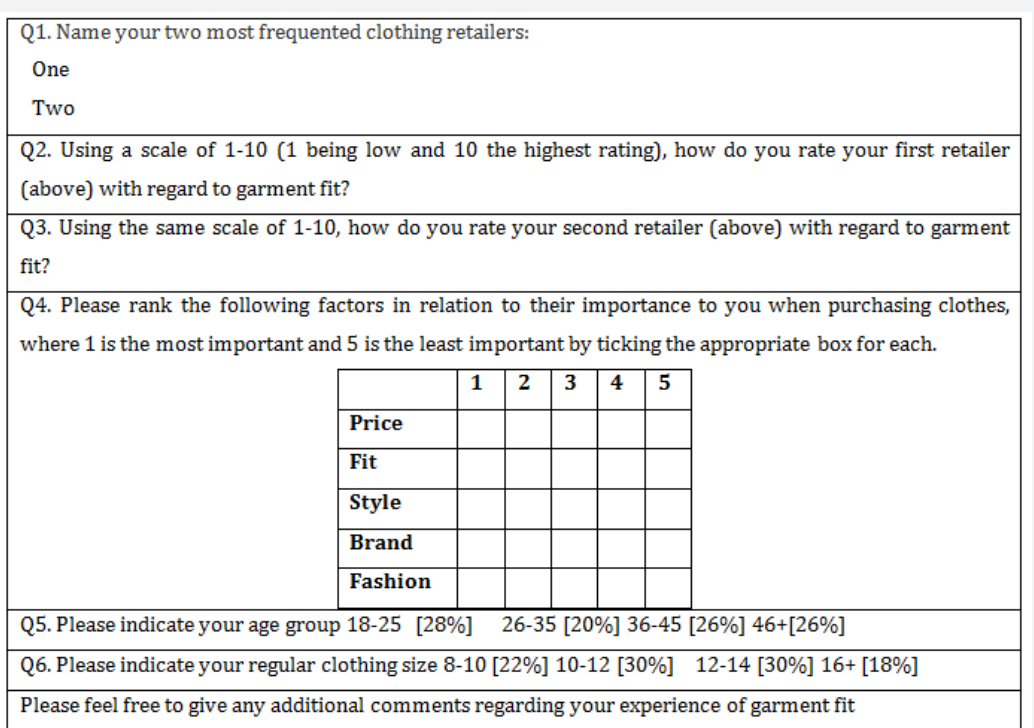

Figure 1: Questionnaire 1.

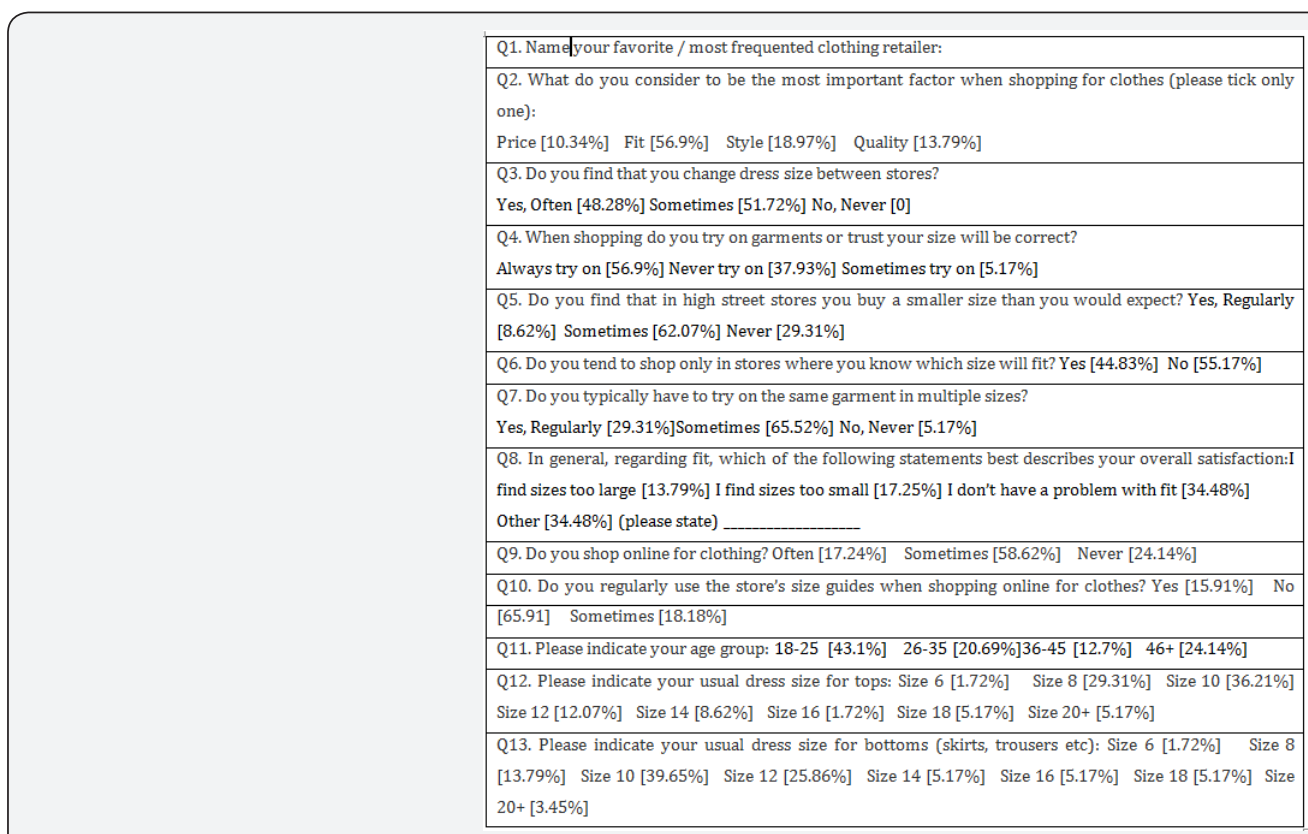

Figure 2: Questionnaire 2. 
An exercise followed to explore variations in women's clothing sizes taking the critical measurements of a UK size 12 shirt and a dress of the same style that cover the bust, waist and hip areas. The garments were selected from the three most mentioned retail stores from the questionnaire surveys. A content analysis-type exercise was then conducted to explore variations in the body measurements that retailers use to standardise their garment sizes. Online size charts were used from the websites of five retailers also selected from the questionnaire survey results; two retailers, $A$ and $B$, represent the younger, fashionfocused segment of the market; two retailers, $C$ and D, represent the mature fashion-oriented consumers and one online retailer, E, that would highly rely on good size communication to lessen the risk of returns. The bust, waist and hip measurements of each retailer's size charts were compared against each other and against Aldrich's (2008: 12) standard body measurements. Finally fit trials were conducted to obtain a deeper insight into opinions regarding garment fit. The body measurements of three participants of the same declared clothing size and age were taken (and later compared) prior to trialling eight garments from three retailers. Each participant gave comments on the fit of each garment. A second fit trial was conducted with six different sized participants incorporating a focus group-type session to further explore opinions regarding fit. Their measurements were also taken and compared with Aldrich's youthful, athletic figure measurements (2008: 12) and mature figure measurements (2008: 13). Each trialled one garment of their size and was questioned about its fit and were also asked to comment on the fit of garments from their most favoured high street retailer. The culmination of the data informs the conceptual re-thinking of the identified fit issues.

\section{Inconsistencies in Size, Labelling and Fit}

Nellis, reporting for Fashion. About.Com, found that according to Stores.org, around $\$ 28$ billion worth of clothing is returned on an annual basis due to poor fit, which supports the ongoing consideration of the inconsistencies in garment sizing. Kinley [12] reiterates [13] had, twenty years previous, found inconsistencies in garment size when in a small-scale exercise 21 of 50 size 8 garments were found to fit a size 12 dress stand with only 10 fitting a size 8 stand. Nellis confirms that this is still apparent today as a standard US size can in reality be two sizes smaller or larger than its label size; though it should be noted that a garment is not always designed to fit snug.

Faust [14] state that the most commonly perceived problem of garment labelling is that size codes typically have no direct correlation to any actual body dimensions. Winks purports that as manufacturers label their garments in many different ways, through ready-to-wear clothing production some confusion regarding how to designate sizes has prevailed and that the variations in size code labels is perplexing for consumers. Winks further explains (1997:2) that manufacturers are not standardised even in the way they base their measurements as some use, for instance, length or chest while others use garment dimensions. Petrova [15] similarly believes variations of size code labelling to be the cause of detrimental miscommunications between consumers and retailers that leads to consumer dissatisfaction and consumers avoiding particular retailers. A Mintel report (2013) confirms this still to be happening stating that $53 \%$ of respondents claim to be put off trying different brands due to inconsistencies in sizing between retailers; and $61 \%$ agree that not knowing if clothing will fit puts them off shopping online for clothing.

In 1993 A bend declared that there was only around a 20$30 \%$ probability that a garment of a particular size would fit a consumer considered to be of that size [12] Nearly twenty years later, Harry Wallop, reporting for The Telegraph (30th September, 2010), discussed a study commissioned by the consumer group Which?, in which they measured the waists of size 12 dresses in eight UK high street stores after finding that nine out of ten women are frustrated about the lack of conformity on the high street. The findings concluded that the differences varied by up to $4 \mathrm{~cm}$, though in reality, in accordance with Aldrich's standard body size measurements, is still slightly less than a subsequent label size increment.

Fay Schlesinger reporting for The Daily Mail (21st April, 2010) found that retailers targeting consumers in their late teens and twenties may be using smaller measurements than a store which appeals to a more mature consumer of the same garment label size, a practice known as vanity sizing. With increased pressure on time and the option to shop online, poorly designed garment labelling coupled with the practice of vanity sizing can only detract from the appeal of fashion shopping. Sean Poulter, also reporting for The Daily Mail (30th September, 2010), stated that whilst retailers may think that 'women would love it if they could slip into a size 12', it is rather frustrating for those consumers who struggle to find consistency between stores.

\section{Sizing as a marketing strategy}

From the retailers' perspective it is important to satisfy the consumer but in a cost effective manner which generally equates to maximum sales from a minimum range of sizes being produced. At present there are no regulations that require companies to use any standardised system and they are known to adapt sizing survey results to develop their own specific sizing systems. This practice has resulted in a range of garment size variances, of which many retailers view as being their 'unique fit' that would be compromised if a single standardised system was used by the industry Ashdown. Therefore sizing systems are typically developed with a target consumer in mind with each retailer using a fit model which they deem to be representative of their target market [16], hence using sizing as a brand image strategy Le Pechoux, Ghosh. However, Chun suggests that companies are wasting their time studying and defining their 
target market if consumers still have difficulty obtaining the right size. With retailers believing that they produce garments that consistently fit their target market, which in turn helps to create brand loyalty, changing their fit could be detrimental to the brand, as found by Brown \& Rice who believe that as long as retailers are meeting sales targets they are unlikely to change their sizing system.

\section{Addressing consumer satisfaction/dissatisfaction}

As Labat states a well designed labelling system should 'spare' consumers 'the frustration of trying on' numerous garments 'to find one that fits'; a task even more frustrating for online shoppers where the demand for accurate and helpful information is more of a necessity Chun. Chun also suggests that garment labelling generates consumer dissatisfaction and believes that if sizing was derived from actual body measurements it would aid sales and benefit customers in terms of fit (2007:220). Previously [17] found consumer dissatisfaction with regards to garment fit being 'as high as $62 \%$ in men and 50\% in women', however, like Brown and Rice, Ashdown and Dunn believe that sizing standardizations may hinder consumers that are not well catered for, may limit size options and continue to isolate those with body shapes that do not fit the proverbial norm. At one extreme, the one-size fits all approach has being taken by some but, as stated by Brown and Rice, fewer consumers are actually catered for as for many their size sits at one end of the spectrum or at the other end. Garments are expected to stretch to fit the larger figure but hangs in an unflattering manner on those of a smaller size, both of which are unflattering, with few consumers in the optimum middle where a good fit could be achieved. At the other extreme [18], suggest that a tailor-made clothing system would render sizing system issues obsolete, however coping with the logistics of mass producing garments in this manner has never being accomplished, even modular production systems as a more flexible approach has never found favour with manufacturers Cassidy, Han.

\section{Body shape and fit preference}

According to Le Pechoux and Ghosh, reluctance from companies to conform to a system that attempts to standardise clothing sizes have failed due to the variety of actual body sizes and body shapes in the population. While Faust state the Triangle; Inverted Triangle; Rectangle; Hour-glass; Diamond and Rounded shapes to be the most common body forms, A Daily Mail Online article (2006) claimed that retailers are still producing clothing based on the less prevalent 'Marilyn Monroe hour-glass figure' of the 1950s, estimating that only around $6 \%$ of women are of this shape today. More recently [19], reporting for The Telegraph, found that understanding one's body shape is more important than knowing your dress size and that there is much to be said in finding brands that work for you, a concept endorsed in the article by Kirsty Attwood, Style Manager for Selfridges.

Furthermore, body shapes vary among countries and races.
Lee [20] investigated the differences between the shapes of US women and Korean women, concluding that the 'rectangle, followed by the 'triangle' shape was more prevalent in Korean women, and the 'spoon' shape among US women. This is an important consideration not only from a global brand perspective where retailers operate in many countries, but also for home countries to take advantage of additional sales generated through tourism. Robson [21] reporting for The Telegraph states body proportion is more important than dress size and that good fit equates to looking [and feeling] good. Therefore the perception of how well a garment fits an individual is subject to that individual's preference for enhancement and concealment as well as the proximity of the garment to the body in terms of the overall aesthetic look and impact on physical comfort.

Previously Alexander [22] found that women prefer a closer fit in areas of the body that they are happy with, thus emphasising those parts, and consequently prefer a looser fit in areas that displease them to conceal, what they believe to be, body faults; this type of satisfaction/dissatisfaction is known as body cathexis [23] and is considered to be an important factor of the fashion shopping experience. Schofield \& LaBat [24] discovered, women would first find fault with their bodies rather than question the validity of the retailers' sizing system. To complicate matters further the exposure and concealment of different areas of the body is personal to the individual and therefore the industry is not in a strong position to be presumptuous in knowing what consumer desires are. Also the rapid style changes inherent of faster moving trends may cause some manufacturers to be less concerned with good fit as consumers know that in another six weeks or so there will be new styles for them to choose from.

However, if as suggested by Mintel [11], quality becomes more important to consumers than price, addressing issues regarding fit may be more pertinent as consumers may be looking to invest in garments that are longer lasting where fit would surely be an intrinsic characteristic of quality. Quality in style, fabrics and production processes are particularly highly desirable virtues of fashion products by purchasers of secondhand or vintage fashion [25]. As there is a strong indication that the industry is unlikely to endorse and develop a standard sizing system in the foreseeable future, understanding how consumers generally cope with the current system when deciding to make fashion purchases is considered to be the best research approach to conceptualise alternative solutions to at least reduce the impact of the problems experienced by consumers in relation to garment fit. This conceptualisation process begins with the findings from the series of surveys that were outlined in the research methods section.

\section{Findings}

Here the findings from the primary research activities are presented and discussed before considering further issues. 


\section{The initial questionnaire}

An initial questionnaire survey was conducted to better understand the UK consumers' perspective of garment fit. Respondents aged18 to 35 collectively (48\%) represent the younger end of the market and those aged 36 and above collectively (52\%) represent the mature market Q5, (Figure 1). Sizes range relatively evenly from UK sizes 8 to $16+$ Q6, (Figure

Table 1: Questionnaire 1 Results for Questions 2 and 3.

\begin{tabular}{|c|c|c|c|c|c|}
\hline \multicolumn{2}{|l|}{ Rating } & $\begin{array}{l}\text { Q2. How do You Rate Your 1st Most } \\
\text { Frequented Retailer Regarding } \\
\text { Garment Fit? }\end{array}$ & & $\begin{array}{l}\text { Q3. How do You Rate Your 2nd Most } \\
\text { Frequented Retailer Regarding Garment Fit? }\end{array}$ & \\
\hline \multirow{3}{*}{ Highly Dissatisfied } & 1 & 1 respondent (2\%) & \multirow{3}{*}{$14 \%$} & 0 respondents $(0 \%)$ & \multirow{3}{*}{$6 \%$} \\
\hline & 2 & 2 respondents ( $4 \%$ ) & & 2 respondents ( $4 \%$ ) & \\
\hline & 3 & 4 respondents $(8 \%)$ & & 1 respondent (2\%) & \\
\hline \multirow{2}{*}{$\begin{array}{l}\text { Moderate } \\
\text { dissatisfaction }\end{array}$} & 4 & 5 respondents $(10 \%)$ & \multirow{2}{*}{$32 \%$} & 8 respondents (16\%) & \multirow{2}{*}{$30 \%$} \\
\hline & 5 & 11 respondents $(22 \%)$ & & 7 respondents $(14 \%)$ & \\
\hline \multirow{2}{*}{ Moderate satisfaction } & 6 & 2 respondents (4\%) & \multirow{2}{*}{$12 \%$} & 4 respondents (8\%) & \multirow{2}{*}{$16 \%$} \\
\hline & 7 & 4 respondents $(8 \%)$ & & 4 respondents (8\%) & \\
\hline \multirow{3}{*}{ Highly Satisfied } & 8 & 3 respondents $(6 \%)$ & \multirow{3}{*}{$40 \%$} & 12 respondents $(24 \%)$ & \multirow{3}{*}{$48 \%$} \\
\hline & 9 & 11 respondents $(22 \%)$ & & 9 respondents (18\%) & \\
\hline & 10 & 7 respondents (14\%) & & 3 respondents (6\%) & \\
\hline
\end{tabular}

Question 4 probed the importance of fit. Six answers were spoiled resulting in 44 responses. The results in Table 2 show fit, style and price to be are more important than brand and fashion. Many noted experiencing variations of fit from garments of the same label size, though style-variations and different ease tolerance consideration should not be disregarded. One
1). Question 1 was used purely to focus respondents on recent shopping experiences the results therefore have no relevance. Questions 2 and 3 were designed to determine the levels of fit satisfaction. The results shown in Table 1 suggest that respondents were marginally more satisfied with the fit obtained from their second favoured retailer, but continue to purchase more frequently from their first favoured retailer suggesting a degree of brand loyalty.

Table 2: Questionnaire 1 Results for Question 4.

\begin{tabular}{|c|c|c|c|c|c|c|c|}
\hline & \multicolumn{3}{|c|}{ Most Important } & \multirow[b]{2}{*}{ Total 1 to 3} & \multicolumn{2}{|c|}{ Least Important } & \multirow[b]{2}{*}{ Total 4 to 5} \\
\hline & 1 & 2 & 3 & & 4 & 5 & \\
\hline Price & $9(20.45 \%)$ & $11(25 \%)$ & 17 (38.63\%) & $84.08 \%$ & $6(13.63 \%)$ & $1(2.27 \%)$ & - \\
\hline Fit & $20(45.45 \%$ & $17(38.63 \%)$ & $3(6.82 \%)$ & $90.9 \%$ & $3(6.82 \%)$ & $1(2.27 \%)$ & - \\
\hline Style & $13(29.54 \%)$ & $11(25 \%)$ & $16(36.36 \%)$ & $90.9 \%$ & $3(6.82 \%)$ & $1(2.27 \%)$ & - \\
\hline Brand & $1(2.27 \%)$ & $1(2.27 \%)$ & $5(11.36 \%)$ & - & $19(43.18 \%)$ & $18(40.91 \%)$ & $84.09 \%$ \\
\hline Fashion & $1(2.27 \%)$ & $4(9.09 \%)$ & $3(6.82 \%)$ & - & 13 (29.54\%) & 23 (52.28\%) & $81.82 \%$ \\
\hline
\end{tabular}

\section{Questionnaire survey 2}

The second survey was conducted to further verify the importance of fit when purchasing clothing and to enquire more deeply into fit related issues. The majority (73.7\%) of the sample represented the younger market Question11; (Figure 2) wearing size 8-10 tops (65.52\%, Q12), (Figure 2) and size 10-12 bottoms (65.51\%, Q13), (Figure 2). Again question 1 was asked simply to focus respondents on the shopping experience. Question 2 is Q4 of the first survey refined to verify the importance of fit, respondent used this to her advantage stating 'I can usually find something to fit me because of fit variations'. Petite consumers tended to blame height and short limbs as being problematic for a good fit, suggesting this to be their burden rather than being that of retailers.

replacing low scoring brand and fashion elements with quality. The findings show fit to be the most important aspect followed again by style, but quality is now more important than price, as can be seen in Figure 3, and concurs with Mintel. Of the 58 respondents, 28 often, and 30 sometimes change sizes between stores (Q3); 33 always, and 22 sometimes try garments on suggesting uncertainty (Q4). Five respondents regularly buy a smaller size than expected, 36 do sometimes and 17 never do (Q5). 


\section{Most important factor when clothes shopping}

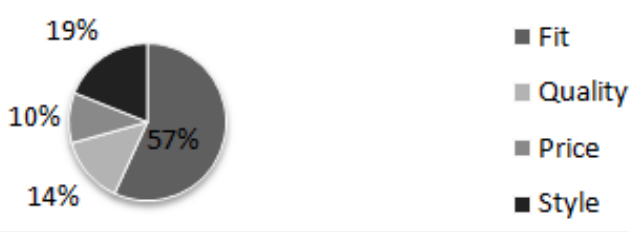

Figure 3: Most Important factor when clothes shopping.

Nearly half of those surveyed [26] favour stores where they know which size will fit (Q6); 17 try multiple sizes and 38 sometimes try multiple sizes to achieve a good fit (Q7). One third (18) find garments in their size too big or too small, 20 have no fit issues and the remaining 20 ticked other (Q8). Comments support the lack of standardisation causing annoyance with sizes not translating across all stores concurring with [26], who found that nine out of ten women are frustrated about the lack of conformity on high streets, but the findings also suggest that many consumers spend time in changing rooms to find a good fit, particularly as one area of the garment may fit well but other areas do not, for example, 'fits the waist but not the hips'. While 14 of the 58 respondents never shop for clothes online, 34 sometimes do and 10 do so often (Q9); of the 44 that do shop online for clothes only 7 regularly use the store's size guides, 8 do sometimes but 28 do not (Q10).

\section{Measurement exercise}

To explore variations in garment size, similar styled garments were measured and compared to [27] size 12 standard measurements, of which an appropriate amount of ease would be added for each garment style.

Table 3: Shirts Measurements in Centimeters.

\begin{tabular}{|c|c|c|c|c|c|}
\hline & Bust & Under-bust & Waist & Hips & Nape to Hem \\
\hline Retailer One & 99 & 119.5 & 114.5 & 127 & 160.5 \\
\hline Retailer Two & 114.5 & 117 & 108 & 124.5 & 159 \\
\hline Retailer Three & 117 & 124.5 & 109.5 & 93 & 165.5 \\
\hline Standard & 87 & - & 69 & $41^{*}$ \\
\hline
\end{tabular}

Comparison of shirts: The shirt measurements varied greatly between the three retailers as shown in Table 3. While differences in measurements may purely be style related the garments look identical in style. The more generous bust sizes offered by retailers two and three may allow for larger women to fit into a smaller label size but on the standard size 12 lady it may not be a flattering fit. Of course, as previously stated, an individual's preference for how the garment looks on them is an important issue that is not explored through this exercise. A standard under-bust measurement is not given by Aldrich, but the under-bust measurements for each garment are more generous than the bust measurement confirming that the style is not designed to fit into the waist as a blouse but to hang loosely as a shirt shaping back into the waist.

This shaping would accommodate ladies' with a larger midriff, as is quite common with women in the UK. Additional shape is given to the garment in the hip area which would allow consumers to purchase a size below their regular size, but again not necessarily a flattering fit for the size 12 lady. The style has short sleeves and therefore sleeve length would not be a fit issue. Using the standard body size measurements given by Aldrich [28], the size 12 shirt from retailer one could comfortably fit a lady up to a dress size 16, size 22 for retailer two and size 24 for retailer three if a more snug fit and look is desirable.

Comparison of Dresses: Overall, retailer two's dress is the smallest but longest and retailer three's dress is the largest. The dress measurements are shown in Table 4. Considering that this garment is designed to be close fitting due to being completely strapless one would have assumed the actual measurements to be very similar to the standard. In fact for retailer one, the bust measurement for the dress is greater than for their shirt. In all cases the under-bust measurement is less than the bust measurement to ensure that the garment fits more snug to the body. Depending on an individual's preference regarding fit, theoretically the dresses from retailers' one and three could comfortably fit a lady up to a dress size 20 and size 16 for retailer two.

Table 4: Shirts Measurements in Centimeters.

\begin{tabular}{|c|c|c|c|c|c|}
\hline & Bust & Under Bust & Wait & Hips & Total Length \\
\hline Retailer one & 107 & 96.5 & 99 & 122 & 158 \\
\hline Retailer two & 99 & 93 & 94 & 132 & 166.5 \\
\hline Retailer three & 109.5 & 99 & 99 & 93 & 160.5 \\
\hline Standard & 87 & - & 69 & \\
\hline
\end{tabular}


Content Analysis Exercise: The five selected retailers have similar guides measuring the bust, waist and hips, however the measurements differ and therefore consumers must undertake the same process for each retailer visited online which may contribute to sizing issues for those unaware of these differences. Each retailer's measurements are shown in centimetres in
Tables 5-7 with Aldrich's standard measurements. All retailers except for a offer sizes 6 to 18; A offers 6 to 16. Aldrich gives body measurements for sizes 6 to 16 for youthful figures and from 6 to 26 for mature figures, as size 18 is the largest size offered Aldrich's sizes 20 and above are omitted from the Tables.

Table 5: Bust Measurements Given by the Five Selected Retailers and Winifred Aldrich's Standard Body Measurement Guides.

\begin{tabular}{|c|c|c|c|c|c|c|c|}
\hline UK size & 6 & 8 & 10 & 12 & 14 & 16 & 18 \\
\hline Retailer A (Younger Fashion Market) & 79.5 & 82 & 87 & 92 & 97 & 102 & - \\
\hline Difference between the standard & 3.5 & 2 & 3 & 4 & 5 & 6 & - \\
\hline Retailer B (Younger Fashion Market) & 76 & 80 & 84 & 88 & 92 & 96 & 100 \\
\hline Difference between the standard & 0 & 0 & 0 & 0 & 0 & 0 & 0 \\
\hline Retailer C (More Mature Fashion Market) & 83.5 & 86 & 91 & 96 & 102 & 108 & 108 \\
\hline Difference between the standard & 7.5 & 6 & 7 & 8 & 10 & 10 & 8 \\
\hline Retailer D (More Mature Fashion Market) & 81.5 & 84 & 89 & 94 & 99 & 104 & 109 \\
\hline Difference between the standard & 5.5 & 4 & 5 & 6 & 7 & 8 & 9 \\
\hline Retailer E (Online Retailer) & 78.5 & 81 & 86 & 91 & 96 & 101 & 108.5 \\
\hline Difference between the standard & 2.5 & 1 & 2 & 3 & 4 & 5 & 8.5 \\
\hline Winifred Aldrich Standard Youthful Figure & 76 & 80 & 84 & 88 & 92 & 96 & - \\
\hline \& Mature Figure & 76 & 80 & 84 & 88 & 92 & 96 & 100 \\
\hline
\end{tabular}

The bust measurements given in Table 5 show Retailer's $\mathrm{A}$ and $\mathrm{E}$ have similar bust measurements suggesting a similar target market and a young fashion style. However, retailer B should also be similar having a similar target market, but is at least $2.5 \mathrm{~cm}$ smaller and is the only retailer to concur with

mature figure bust measurements are alike. Retailers' C and D have similar measurements as expected as they target the more mature market and are considerably larger than the standard, with the exception of retailer B there is no consistency between the measurement discrepancies. Aldrich's standard body sizes; note Aldrich's youthful and Table 6: Waist measurements given by the five selected retailers and Winifred Aldrich's standard body measurement guides.

\begin{tabular}{|c|c|c|c|c|c|c|c|}
\hline UK size & $\mathbf{6}$ & $\mathbf{8}$ & $\mathbf{1 0}$ & $\mathbf{1 2}$ & $\mathbf{1 4}$ & $\mathbf{1 6}$ & $\mathbf{1 8}$ \\
\hline Retailer A (Younger Fashion Market) & 62.4 & 64.9 & 69.2 & 74.2 & 79.2 & 84.2 & - \\
\hline Difference between the standard & 6.4 & 4.9 & 5.2 & 6.2 & 7.2 & 8.2 & - \\
\hline Retailer B (Younger Fashion Market) & 60 & 64 & 68 & 72 & 76 & 80 & 84 \\
\hline Difference between the standard & 4 & 4 & 4 & 4 & 4 & 4 & 0 \\
\hline Retailer C (More Mature Fashion Market) & 63.5 & 66 & 71 & 76 & 82 & 88 & 94 \\
\hline Difference between the standard & 3.5 & 2 & 3 & 4 & 6 & 8 & 10 \\
\hline Retailer D (More Mature Fashion Market) & 63.5 & 66 & 71 & 76 & 81 & 86 & 91 \\
\hline Difference between the standard & 3.5 & 2 & 3 & 4 & 5 & 6 & 7 \\
\hline Retailer E (Online Retailer) & 60.5 & 63 & 68 & 73 & 78 & 83 & 90.5 \\
\hline Difference between the standard & 4.5 & 3 & 4 & 5 & 6 & 7 & 6.5 \\
\hline Winifred Aldrich Standard Youthful Figure & 56 & 60 & 64 & 68 & 72 & 76 & - \\
\hline \& Mature Figure & 60 & 64 & 68 & 72 & 76 & 80 & 84 \\
\hline
\end{tabular}

The waist measurements in Table 6 show the differences in the measurements for retailers' A, B and E are given in relation to the youthful figure standard, except for size 18 which uses the mature figure standard, and for $\mathrm{C}$ and $\mathrm{D}$ in relation to the mature figure standard in line with each retailer's target market. Note there is a consistent $4 \mathrm{~cm}$ difference between the measurements of these two standards. Retailers A and E are again very similar. Retailers C and D's measurements are almost identical and not greatly different from the mature figure measurements given by Aldrich for the smaller sizes. The waist measurements of Retailer B concur with Aldrich's mature figure measurements.

The waist measurements in Table 6 show the differences in the measurements for retailers' A, B and $\mathrm{E}$ are given in relation to the youthful figure standard, except for size 18 which uses the mature figure standard, and for $\mathrm{C}$ and $\mathrm{D}$ in relation to the mature 
figure standard in line with each retailer's target market. Note there is a consistent $4 \mathrm{~cm}$ difference between the measurements of these two standards. Retailers A and E are again very similar. Retailers C and D's measurements are almost identical and not greatly different from the mature figure measurements given by Aldrich for the smaller sizes. The waist measurements of Retailer B concur with Aldrich's mature figure measurements.

The hip measurements in Table 7 show Retailer A's size 6 concurs with Aldrich's mature figure size 6 measurements. Sizes
8 and 10 gravitate more towards the younger figure but migrates back to the mature figure measurements for the larger sizes. Whereas Retailer B's measurements, who also caters for the younger fashion consumer, concurs with Aldrich's mature figure measurements. Retailer E's measurements are consistently slightly larger than B and slightly larger than the mature figure measurements. Retailers C and D's hip measurements are significantly larger than Aldrich's standard mature figure measurements, with Retailer C's size 14 being the same as Aldrich's size 18.

Table 7: Hip Measurements Given by the Five Selected Retailers and Winifred Aldrich's Standard Body Measurement Guides.

\begin{tabular}{|c|c|c|c|c|c|c|c|}
\hline UK size & $\mathbf{6}$ & $\mathbf{8}$ & $\mathbf{1 0}$ & $\mathbf{1 2}$ & $\mathbf{1 4}$ & $\mathbf{1 6}$ & $\mathbf{1 8}$ \\
\hline Retailer A (Younger Fashion Market) & 84 & 86.5 & 91.5 & 96.5 & 101.5 & 106.5 & - \\
\hline Difference between the standard & 2 & 0.5 & 1.5 & 2.5 & 3.5 & 4.5 & - \\
\hline Retailer B (Younger Fashion Market) & 84 & 88 & 92 & 96 & 100 & 104 & 108 \\
\hline Difference between the standard & 2 & 2 & 2 & 2 & 2 & 2 & 2 \\
\hline Retailer C (More Mature Fashion Market) & 89.5 & 92 & 97 & 102 & 108 & 114 & 120 \\
\hline Difference between the standard & 5.5 & 4 & 5 & 6 & 8 & 10 & 12 \\
\hline Retailer D (More Mature Fashion Market) & 88.5 & 91 & 96 & 101 & 106 & 111 & 116 \\
\hline Difference between the standard & 4.5 & 3 & 4 & 5 & 6 & 7 & 8 \\
\hline Retailer E (Online Retailer) & 86 & 88.5 & 93.5 & 98.5 & 103.5 & 108.5 & 116 \\
\hline Difference between the standard & 4 & 2.5 & 3.5 & 4.5 & 3.5 & 6.5 & 8 \\
\hline Winifred Aldrich Standard Youthful Figure & 82 & 86 & 90 & 94 & 98 & 102 & - \\
\hline \& Mature Figure & 84 & 88 & 92 & 96 & 100 & 104 & 108 \\
\hline
\end{tabular}

The hip measurements in Table 7 show Retailer A's size 6 concurs with Aldrich's mature figure size 6 measurements. Sizes 8 and 10 gravitate more towards the younger figure but migrates back to the mature figure measurements for the larger sizes. Whereas Retailer B's measurements, who also caters for the younger fashion consumer, concurs with Aldrich's mature figure measurements. Retailer E's measurements are consistently slightly larger than B and slightly larger than the mature figure measurements. Retailers C and D's hip measurements are significantly larger than Aldrich's standard mature figure measurements, with Retailer C's size 14 being the same as Aldrich's size 18.

The hip measurements in Table 7 show Retailer A's size 6 concurs with Aldrich's mature figure size 6 measurements. Sizes 8 and 10 gravitate more towards the younger figure but migrates back to the mature figure measurements for the larger sizes. Whereas Retailer B's measurements, who also caters for the younger fashion consumer, concurs with Aldrich's mature figure measurements. Retailer E's measurements are consistently slightly larger than B and slightly larger than the mature figure measurements. Retailers C and D's hip measurements are significantly larger than Aldrich's standard mature figure measurements, with Retailer C's size 14 being the same as Aldrich's size 18.

Through this exercise it can be appreciated that retailers use sizing strategically but rely on consumers purchasing online to know or to accurately take their own body measurements, a simple enough task. However as evident from the previous exercise the actual garment measurements of the same label size garments can differ greatly between retailers. As actual garment measurements are not communicated to consumers online, other than perhaps length, consumers have no way of knowing how well the garments will fit in relation to their own measurements or how the fit will meet personal preferences or levels of acceptance.

Table 8: Participant's Body Measurements in Centimeters.

\begin{tabular}{|c|c|c|c|}
\hline Key Dimensions & Participant 1 & Participant 2 & Participant 3 \\
\hline Bust & 85.5 & 94.5 & 84 \\
\hline Under bust & 78 & 77 & 70 \\
\hline Waist & 68.5 & 71 & 66 \\
\hline Upper Hip & 89 & 88.5 & 82 \\
\hline Lower Hip & 95.5 & 100 & 97.5 \\
\hline
\end{tabular}




\section{Current Trends in Fashion Technology \& Textile Engineering}

\begin{tabular}{|c|c|c|c|}
\hline Inside Leg & 82.5 & 84.5 & 76 \\
\hline Arm Length & 58.5 & 53 & 51.5 \\
\hline Shoulder to shoulder & 43 & 36.5 & 40.5 \\
\hline Height & 173 & 169 & 166 \\
\hline
\end{tabular}

Fit Sessions: The fit sessions were used to query fit related issues in real terms. Eight garments were used: a shirt-style top, an A-line style top, a pair of trousers, a pair of jeans, a shiftstyle dress (1), a tube-style dress (2), a pencil skirt (1) and a mini skirt (2). The measurements of the three participants are given in Table 8. All of the measurements vary widely, yet they all declared wearing the same size clothing. The waist, upper hip and lower hip measurements have the least variations in size between the three participants. The arm length and shoulderto-shoulder measurements have the largest variation, but as control dimensions these appear to be rarely used.

Jeans and Trousers: Participant one had issues with the length of the trousers and jeans, the body measurements confirm the issue, as she was the tallest of the participants, and had the longest inside leg measurement. Participant two found that the jeans were too short, but the length of the trousers was not an issue. Participant three's inside leg measurement is $8.5 \mathrm{~cm}$ shorter than participant two's yet she said that the trousers fit perfectly. This may suggest that shorter women accept that they are not well catered for and that length issues may be taken care of via alterations as found by Yoo [29], or by simply wearing heals. Participant two felt that the jeans were too tight across her thighs, and that the back rise was too short, which would leave her exposed if she bent down. She has the biggest hips and stated that she would wear the jeans lower down her body to compensate. Participants one and three thought that the jeans gave a good fit around the hips and across the seat.

Dresses: Participant two found dress (1) tight across the chest, whereas participant three found it loose and participant one thought that it was a good fit; the comments coincide with their bust measurements. Participant two's bust measurement is more like a size 14 according to Aldrich's Table of body measurements. Similarly participant three's bust measurement is more that of a size 10, she commented on dress (2) being far too loose across the chest. Participant two deemed this dress unacceptable to wear, as it would fall down with too much movement and Participant one also found this dress to be loose across the bust. This may be the manufacturer's way of catering for women with a small body and fuller bust.

Tops: Participant three said that top (1) was quite loose around the biceps, which participant one agreed with, and added that it could have been the style of the garment. It appears that some take style into account when considering the fit and may declare some styles unsuitable for them based on their fit experiences. Participant one felt that the upper chest of top (2) was tighter than she would have preferred, and it would be difficult to stretch her arms behind her back without damaging the top. She also had issues with the sleeve length on top (2), stating that they could be a bit longer, whereas participant three would have preferred the sleeves to be shorter. Comparing their arm length measurements to Aldrich's Standard Body measurements participant one's arms match her height, whereas participant three's arms are shorter than average for her height. Participant two, who matched the standard body measurements for sleeve length, had no complaints with the length of the sleeves, considering it to be a good fit.

Participant two's bust size did however cause problems again with top (2) which gaped across the largest part of the bust. With the exception of this, she found the shirt to be a good fit, and would definitely consider buying it. Consumers whose body dimensions to do not conform to their clothing size e.g. large bust for the clothing size, are prepared to buy garments that do not provide good fit in one area to satisfy the fit of other dimensions. Gaping is often an issue for consumers with a larger bust when purchasing shirts, and tops with buttons, which may simply be due to the positioning of the buttons. Again, the acceptance, or tolerance of this issue depends on the individual.

Table 9: Fit Trial Participant's Measurements and Aldrich's Standard Measurements.

\begin{tabular}{|c|c|c|c|c|c|c|c|}
\hline UK size & 6 & 8 & 10 & 12 & 14 & 16 & 18 \\
\hline Retailer A (Younger Fashion Market) & 84 & 86.5 & 91.5 & 96.5 & 101.5 & 106.5 & - \\
\hline Difference between the standard & 2 & 0.5 & 1.5 & 2.5 & 3.5 & 4.5 & - \\
\hline Retailer B (Younger Fashion Market) & 84 & 88 & 92 & 96 & 100 & 104 & 108 \\
\hline Difference between the standard & 2 & 2 & 2 & 2 & 2 & 2 & 2 \\
\hline Retailer C (More Mature Fashion Market) & 89.5 & 92 & 97 & 102 & 108 & 114 & 120 \\
\hline Difference between the standard & 5.5 & 4 & 5 & 6 & 8 & 10 & 12 \\
\hline Retailer D (More Mature Fashion Market) & 88.5 & 91 & 96 & 101 & 106 & 111 & 116 \\
\hline Difference between the standard & 4.5 & 3 & 4 & 5 & 6 & 7 & 8 \\
\hline Retailer E (Online Retailer) & 86 & 88.5 & 93.5 & 98.5 & 103.5 & 108.5 & 116 \\
\hline
\end{tabular}




\section{Current Trends in Fashion Technology \& Textile Engineering}

\begin{tabular}{|c|c|c|c|c|c|c|c|}
\hline Difference between the standard & 4 & 2.5 & 3.5 & 4.5 & 3.5 & 6.5 & 8 \\
\hline Winifred Aldrich Standard Youthful Figure & 82 & 86 & 90 & 94 & 98 & 102 & - \\
\hline \& Mature Figure & 84 & 88 & 92 & 96 & 100 & 104 & 108 \\
\hline
\end{tabular}

Skirts: Both participants one and two felt that skirt (1) had a really good fit, participant three said that it was slightly baggy. She also said that she felt that the size smaller would have been too tight and would not have purchased this skirt. This would indicate that consumers do consider how a smaller or larger size may fit if there is an issue with the size they try on. It may be fair to assume that some will conclude that another size will not provide a better fit without trying on anticipating the size difference and that some may try a different size to be sure. Participants two and three both found the lining of skirt two to be too tight, and felt that it would restrict their movement. Participant one did not agree with this, as she thought it was acceptable for her. She did however, have an issue with the waistband, as she felt it was a bit loose. Interestingly participant three who has smaller waist and hip measurements (Table 9) than participant one did not have any issues with the waistband.

\section{Fit trials}

The fit trials were used to further query fit issues and opinions. Six participant's trialled garments in their usual clothing size after their body measurements had being taken. The measurements are given in Table 9 in centimetres. Aldrich's standard size equivalent is given for the bust, waist and hip measurements in brackets with $Y$ for the younger figure standard and $\mathrm{M}$ for the mature figure standard. In addition participants were asked which retailer they regularly purchase from and to comment on the fit of their trial garment in relation to their experiences of purchasing fashion garments on the high street. Participant 1 trialled a Retailer A size 10 top, which she found it to be too big around the waist and stated that she would not purchase it for this reason. As the top was styled to be quite close fitting the desired look was not achieved. She stated her favourite retailer but complained that her size in this store does not translate to other stores; she finds Retailer B's same size garment too small and a particular third party retailer too big. Participant 2 trialled a size 10 Retailer A top and found that it fitted well. She stated Retailer B as her favourite due to price and that she is willing to spend more time trying on garments of varying styles to find the correct fit.

Participant 3 trialled a Retailer B size 8 top which was too small across the bust however, she said that if the price was affordable and the design was attractive then she would purchase the garment. This suggests that due to her larger bust, she tolerates a sub-standard fit for the sake of style and price. She stated a third party retailer to be her favourite due to their cheaper price points. Participant 4 trialled a size 12 top from the online Retailer E which fit well across the bust and arms but was tight around the waist, this was expected from her measurements. She stated that she would purchase the top based on fit alone, which suggests that she would choose clothing that fits across the bust and compromises on the fit of the waist. She chose her favourite retailer due to convenience and stated that her size varies in this store depending on the style of the garment.

Participant 5 trialled a size 18 top also from the online Retailer E which fitted her well across the bust but was uncomfortably tight around the waist; she said that she would not purchase it even if the style and price were good. Although Retailer E now caters for plus-size consumers she said that she would be unlikely to shop there as she often experiences difficulties with size, and would not purchase something which she could not try on first. She declared a third party retailer as her favourite because they have a wider range of choice for plus size shoppers. She also said that her size is different across the high street, which may be due to retailers using different grading systems for larger sizes.

Participant 6 trialled the same size 18 Retailer E top as participant 5, on her it was a tighter fit across the bust and around the waist, but was a good fit through the arms and shoulders, she said that she would not purchase. When asked if she would use an online service, she said that she would prefer to try on before buying but if she had a relationship with the brand and was confident about their sizing she would then be more likely to use it. She also stated a third party retailer as her favourite as she always knows what size to choose.

\section{Summary of The Findings and Re-Thinking Fit}

The findings from the literature review indicate that fit satisfaction is personal to the individual on how they prefer to wear their clothes and dependent on which areas of their body they wish to conceal with a looser fit and which areas they wish to emphasise with a more snug and revealing fit. From the retailer's perspective differences in fit allow brands to work with their own sizing standards as a strategic marketing method to complement their brand image. The confusion and dissatisfaction among consumers arises when they are unsure of which size will provide them with the best fit. This can deter individuals from trying other brands, particularly if time is of the essence, and deter from shopping for garments on-line due to the hassle of returning products. The problem with fit is furthered when shopping for vintage and retro fashion due to changes over time to the standard size models used by the industry; generally the average lady was smaller in height and girth compared to today's average Chronically [30].

The findings from the primary research agree that a degree of brand loyalty is exercised but for price and convenience rather than for best fit. This is confirmed further through the questionnaire surveys where respondents declared a preference 
of fit achieved by their second favourite retailer than that achieved from their first choice. Individuals who recognise and accept that their body size / shape is different to the average standard sizes are willing to compromise more and may seek alterations to the garment after it is purchased. A lack of confidence in purchasing garments without first trying them on is evident, and many view this as being a barrier to online shopping; though some are willing to try on many garments to realise the best fit before buying. Large discrepancies were found among the measurements of actual garments and the standard sizes given by retailers on their online size charts which reinforces the brand image thinking as a reason for the discrepancies but also emphasises the fit issue from a consumers' perspective.

From discussions with women during the fit trials, it was apparent that although fit was extremely important, to some it would be compromised either to achieve a good fit on other areas of the body, for style or for a cheaper price point. It was found in general that the younger consumers were more price conscious therefore shopped at stores where they could purchase stylish clothing at low prices, compromising on size and fit. For the more mature plus-size participants fit was the main criteria and they would not purchase a garment, despite its style, if they were not satisfied with the fit.

From the findings we can deduce that ideally consumers would try garments on prior to purchase to ensure a good fit, or failing this can easily realise an acceptable fit from the dimensions and style of a garment. This would suggest that the communication of actual garment dimensions may better serve consumers. The crux of the issue here is satisfaction, for the consumer to be able to purchase desirable garments that will fit the body in a manner that is pleasing to them, and for the industry to generate sales. In an attempt to achieve this some kind of immediate, or spontaneous attachment is required. Schifferstein [31] refer to the 'strength of the emotional bond a consumer experiences with a product' as being a critical factor of a person's relationship with a product. While their research is concerned with sustainability whereby design could facilitate the emotional bond over time through ownership, it is easy to understand that those first emotional experiences with products also affect the decision to purchase.

It was evident during the fit trials that trying on a garment that does not necessarily fit the body well in terms of actual measurements [32-36], seeing oneself in that particular garment was in some cases enough of a feel good factor to promote the positive responses towards the garment. It is therefore suggested that encouraging consumers to try garments on is vital to initiating immediate or spontaneous attachment. What needs then to be avoided is disappointment which will ultimately lead to dissatisfaction and a non-sale. This may not be entirely due to the appearance of the garment other factors may come into force [37]. These factors may include the consumer's state of mind or mood at that moment in time, and the environment in which a consumer tries on garments; one's own home may be more preferable due to familiarity and comfort, in which case retailers may also need reconsider their changing room environment to make the process a more integrated and enjoyable part of the shopping experience. However, we must still return to the main point in question, as Labat states consumers should be spared the frustration of trying on numerous garments in order to find one that fits. Therefore a sizing or labelling communication system that reduces the risk of disappointment at the same time as facilitating early emotional attachment would be desirable. Such a communication system is now the focus of further research.

\section{Conclusion}

In this paper fit has been discussed and explored predominantly from a consumer perspective in relation to both the first- and the second-cycle fashion retail sectors in order to conceptually rethink the on-going fit paradigm and debate. The literature review makes reference to the complexity of issues from both the retailers' and consumers' perspectives. A series of primary research activities undertaken are described and the findings discussed to meet the research objectives. In the first instance two questionnaire surveys were conducted, the first to establish relationships between fit and brand loyalty, the second to better understand the importance of fit in relation to the shopping experience and to further explore consumer satisfaction. Variations in body and garment size were explored through a series of exercises which include a comparison of on-line size chart information from a selection of retailers and a content analysis-type exploration using a small selection of comparative garment styles of the same size from a select range of retailers.

Fit trials were then conducted to see the effect of the body and garment size variations in action coupled with discussions and a focus group style activity with respondents to further explore personal opinions in relation to fit. The findings were summarised and research into emotional attachment, which is currently beyond current research into the initial problem of fit, was introduced to aid the conceptualisation of a solution. The paper concludes by suggesting contrary to previous research in this area that there is no proposal to change the current sizing and labelling system but to continue along a pathway that explores avenues to develop a communication system to better inform consumers of the fit of fashion garments, both new and used, in relation to their own body size and shape. This rethinking of a solution has led to further research in this area.

\section{References}

1. Ashdown, Susan P (2007) Sizing in clothing: Developing effective sizing systems for ready-to-wear clothing, Cambridge, Wood head in association with The Textile Institute, UK.

2. Brown, Patty, Janett Rice (2001) Ready-To-Wear Apparel Analysis. ( $3^{\text {rd }}$ Edn.), Prentice Hall, New Jersey, USA.

3. Cassidy, Tracy Diane, Hannah Rose Bennett (2012) The rise of vintage fashion and the vintage consumer. Journal of Fashion Practice 4(2): 241-264. 
4. Nellis, Cynthia (2013) All about fit: Why don't clothes ever fit?

5. Lewis, Van Dyk (2007) Sizing and clothing aesthetics. In: Susan Ashdown Sizing in clothing, Developing effective sizing systems for ready-to-wear clothing, Cambridge, Wood head, UK, pp. 309-327.

6. LaBat, Karen (2007) Sizing standardization. In: Susan Ashdown Sizing in clothing, developing effective sizing systems for ready-to-wear clothing, Cambridge, Wood head, UK, pp. 88-107.

7. Le Pechoux, Tushar Ghosh B (2002) Apparel Sizing and Fit. The Textile Institute International 32(1): p. 1-59.

8. Bougourd, Jennifer (2007) Sizing systems, fit models and target markets. In: Susan Ashdown Sizing in clothing; Developing effective sizing systems for ready-to-wear clothing, Cambridge, Wood head, UK, pp. 108-151.

9. Winks, John (1997) Clothing Sizes International Standardization. Manchester. The Textile Institute, UK.

10. Chun, Jongsuk (2007) Communication of sizing and fit. In: Susan Ashdown Sizing in clothing, Developing effective sizing systems for ready-to-wear clothing, Cambridge, Wood head, UK, pp. 220-245.

11. Mintel (2013) Women's wear UK April 2013.

12. Kinley, Tammy (2003) “Size Variation in Women’s Pants.” Clothing and Textiles Research Journal 21 (1): 19-31

13. Tamburrino N (1992) Sized to Sell Bobbin. 33(7): pp. 68-74. In: Tammy Kinley (2003) Size variations in women's pants. Clothing \& Textiles Research Journal 21(1): pp. 19-31.

14. Faust, Marie-Eve, Serge Carrier, Pierre Baptiste (2006) Variations in Canadian women's ready-to-wear standard sizes. Journal of Fashion Marketing and Management 10(1): 71-83.

15. Petrova, Adriana (2007) Creating sizing systems. In: Susan Ashdown Sizing in clothing; Developing effective sizing systems for ready-towear clothing, Cambridge, Wood head, UK, p. 57-87.

16. Ashdown, Susan, Lindsay M Lyman-Clarke, Jack Smith, Suzanne Loker (2007) Production systems, garment specification and sizing. In: Susan P Ashdown Sizing in clothing: Developing effective sizing systems for ready-to-wear clothing, Cambridge, Wood head, UK, pp. 348-375.

17. Ashdown, Susan and Lucy Dunne (2006) A Study of Automated Custom Fit: Readiness of the Technology for the Apparel Industry. Clothing \& Textiles Research Journal 24(2): 121-135.

18. Daanen, Hein, Peter Reffeltrath (2007) Function, fit and sizing. In: Susan Ashdown Sizing in clothing; Developing effective sizing systems for ready-to-wear clothing, Cambridge, Wood head, UK, pp. 202-219.

19. Finnigan, Kate (2010) Labels to suit your shape.

20. Lee, Joo Young, Cynthia Istook, Yun Ja Nam, Sun MI Park (2007) Comparison of body shape between USA and Korean women.
International Journal of Clothing Science and Technology 19(5): pp. 374-391.

21. Robson, Julia (2013) Jeans Geniuses.

22. Alexander, Marina, Lenda Jo Connell, Ann Beth Presley (2005) Clothing fit preferences of young female adult consumers. International Journal of Clothing Science and Technology 17(1): 52-64.

23. Fan, Jintu, Winnie Yu and Lawrence Hunter (2004) Clothing appearance and fit: Science and technology, Cambridge, Wood head, UK.

24. Schofield, Nancy, Karen LaBat (2005) Exploring the Relationships of Grading, Sizing, and Anthropometric Data. Clothing \& Textiles Research Journal 23(1): pp. 13-25.

25. Cassidy, Tracy Dianeand Sara Han (2013) Up cycling Fashion. In: Gardetti, Miguel Angel, Ana Laura Torres (Eds.), Sustainable Fashion \& Textiles, Sheffield, Greenleaf Publishing, UK, pp. 148-163.

26. Wallop, Harry (2010) High street size 12 varies by $4 \mathrm{~cm}$.

27. Aldrich, Winifred (2004) Metric pattern cutting for Women's wear. ( $4^{\text {th }}$ edn), Oxford, Blackwell, UK.

28. Aldrich, Winifred (2008) Metric pattern cutting for Women's wear. ( $5^{\text {th }}$ edn), Oxford, Blackwell, UK.

29. Yoo, Seulhee, Sarah Khan, Rutherford-Black C (1999) Petite and tallsized consumer segmentation: Comparison of fashion involvement, pre-purchase clothing satisfaction and clothing need. Journal of Fashion Marketing and Management 3(3): pp. 219-235.

30. Chronically Vintage Blog.

31. Schifferstein, Hendrick NJ, Elly Zwartkruis-Pelgrim PH (2008) Consumer-Product attachment: Measurement and design implications. International Journal of Design 2(3): 1-14

32. Abend, Jules (1993) Our fits over fit. Bobbin 34: 78-79. In: Kinley, Tammy R (1993) Size variations in women's pants. Clothing \& Textiles Research Journal 21(1): 19-31.

33. Bye, Elizabeth, Karen LaBat, Marilyn DeLong (2006) Analysis of Body Measurement Systems for Apparel. Clothing \& Textiles Research Journal 24(2): 66-77.

34. Daily Mail Online (2006) Shoppers still try clothes for Marilyns.

35. Petrova, Adriana (2007) Creating sizing systems. In: Susan Ashdown Sizing in clothing; Developing effective sizing systems for ready-towear clothing, Cambridge, Wood head, UK, p. 57-87.

36. Poulter, Sean (2010) The vanity sizing swindle: How shops change clothes sizes to flatter their customers.

37. Schlesinger, Fay (2010) Why your size 10 dress may actually be a size 12. 
CC This work is licensed under Creative
Your next submission with Juniper Publishers will reach you the below assets

- Quality Editorial service

- Swift Peer Review

- Reprints availability

- E-prints Service

- Manuscript Podcast for convenient understanding

- Global attainment for your research

- Manuscript accessibility in different formats

( Pdf, E-pub, Full Text, Audio)

- Unceasing customer service

Track the below URL for one-step submission https://juniperpublishers.com/online-submission.php 